\title{
Surface modeling of ecosystem responses to climatic change in Poyang Lake Basin of China
}

\author{
Tian-Xiang Yue ${ }^{\mathrm{a}, *}$, Zheng-Ping Du ${ }^{\mathrm{a}}$, Ming Lu ${ }^{\mathrm{a}, \mathrm{c}}$, Ze-Meng Fan ${ }^{\mathrm{a}}$, Chen-Liang Wang ${ }^{\mathrm{a}}$, \\ Yong-Zhong Tian ${ }^{\mathrm{b}}$, Bing Xu ${ }^{\mathrm{c}, \mathrm{d}}$ \\ a State Key Laboratory of Resources and Environment Information System, Institute of Geographical Sciences and Natural Resources Research, 11A, Datun \\ Road, Anwai, Beijing 100101, China \\ ${ }^{\mathrm{b}}$ School of Geographical Sciences, Southwest University, China \\ ' School of Environment, Tsinghua University, Beijing 100084, China \\ ${ }^{\mathrm{d}}$ College of Global Change and Earth System Science, Beijing Normal University, Beijing 100875, China
}

\section{A R T I C L E I N F O}

\section{Article history:}

Available online 27 September 2014

Keywords:

Climate change

HASM

Accuracy

Holdridge life zone

Mean center

Response

\begin{abstract}
A B S T R A C T
Surfaces of mean annual temperature and mean annual precipitation during the period from 1951 to 2010 in Jiang-Xi province (Poyang Lake Basin) of China are simulated by means of a method for high accuracy surface modeling (HASM), using data from 106 weather observation stations scattered over and around Poyang Lake Basin. Methodologically, we analyzed errors of HASM by comparing with classical methods. The analysis indicated that HASM has a much higher accuracy than the classical methods. The simulation results from HASM show that mean annual temperature was respectively $17.05^{\circ} \mathrm{C}$ and $17.46^{\circ} \mathrm{C}$ in the periods from 1951 to 1980 (P1) and from 1981 to 2010 (P2). Mean annual precipitation was $1602 \mathrm{~mm}$ and $1718 \mathrm{~mm}$, respectively in the P1 and P2. In other words, climate has become warmer and wetter in recent 60 years in general. The ecosystems are very sensitive to relatively small changes in surface meteorology. Warm temperate moist forest and subtropical moist forest were the dominant HLZ types, accounted for $94.99 \%$ of total area of Jiang-Xi province. The proportion of warm temperate moist forest decreased from $30.81 \%$ to $16.84 \%$, while subtropical moist forest increased from $64.79 \%$ to $76.73 \%$. The mean centers of the rare HLZ types, cool temperate wet forest, cool temperate rain forest and subtropical wet forest, moved respectively $291 \mathrm{~km}, 104 \mathrm{~km}$ and $122 \mathrm{~km}$. Warm temperate wet forest and subtropical moist forest had a little shift, moved respectively $21 \mathrm{~km}$ and $17 \mathrm{~km}$ during the period from P1 to P2.
\end{abstract}

(c) 2014 Elsevier B.V. All rights reserved.

\section{Introduction}

Warming of the climate system is unequivocal, and since the 1950s, many of the observed changes are unprecedented over decades to millennia (IPCC, 2013). Simulating ecosystem responses to climatic change is a central interest of terrestrial ecosystem studies. The related studies can be exhibited in chronological sequence as follows.

A simulated result suggested that forests may respond dramatically and rapidly to global warming, with significant and readily observable changes in forests of mid-latitudes occurring by the turn of the century or shortly thereafter (Botkin and Nisbet, 1992). A study in northern Michigan of USA indicated that climate changes could lead to ecologically and commercially significant

\footnotetext{
* Corresponding author. Tel.: +86 1064889041 .

E-mail address: yue@lreis.ac.cn (T.-X. Yue).
}

changes in the composition and productivity of these forests (Reed and Desanker, 1992). An individual-based forest simulator suggested that forest zones could be shifted on the order of $500-1000 \mathrm{~m}$ in elevation, which could lead to the local extirpation of some high-altitude species (Urban et al., 1993).

Global warming created a zigzag pattern of biomass distribution along a latitudinal gradient, i.e., an increase in the cooler-side boundary of forest types and a decrease in the warmer-side boundary (Kohyama and Shigesada, 1995). The timing and magnitude of future changes in forest systems will depend on environmental factors such as a changing global climate, an accumulation of $\mathrm{CO}_{2}$ in the atmosphere, and increase global mineralization of nutrients such as nitrogen and sulfur (Dixon and Wisniewski, 1995). Depending on the global change scenario used, 4-9 species would potentially move out of the United States to the north. Nearly half of the species assessed (36 out of 80 ) showed the potential for the ecological optima to shift at least $100 \mathrm{~km}$ to the north (Iverson and Prasad, 1998). A simulation by an ecosystem 
process model with a spatial landscape model indicated that boreal species would disappear from the landscape in 200-300 years and approximately same amount of time for a southern species to become common (He et al., 1999). Changes in both climate and $\mathrm{CO}_{2}$ will lead to changing phenological relationships between introduced and native forest insects and their host trees, which could either exacerbate or attenuate damage caused by these pests (Simberloff, 2000).

Response surface simulations indicated that changes in the potential distribution of tree and shrub taxa in North America in response to future climate change will be large and that ranges will shift not only northward and upward in elevation but in all directions (Shafer et al., 2001). The simulations for GCM-projected future climate scenarios with doubled atmospheric $\mathrm{CO}_{2}$ concentration predicted that broadleaf forests would increase, but conifer forests, shrubs and grasses would decrease; and that deciduous forests would have the largest relative increase, but evergreen shrubs would have the largest decrease (Yu et al., 2002). A metaanalysis showed that the range limits of species have moved on average $6.1 \mathrm{~km}$ per decade northward (Parmesan and Yohe, 2003). A review indicated that tropical forest responses to ongoing environmental change are complex because effects of many simultaneously changing environmental factors are integrated by the plants, and their responses can involve significant lags and non-linearities (Clark, 2007). A simulation inference is that the forest as a whole may be buffered from extreme drought events that only affect early life-history stages (McMahon et al., 2009). Simulation from perspectives of ecophysiology, resource availability, and climate change showed that boreal forest responses to climate change are complex due to the inherent edaphic variations and ecophysiological responses (Ise and Moorcroft, 2010). Increases in the frequency, duration, and/or severity of drought and heat stress associated with climate change could fundamentally alter the composition, structure, and biogeography of forests (Allen et al., 2010).

According to results from a combination of an integrated environmental model and climate envelope models, more than $35 \%$ of the species composition in 2100 will be new in Northern Europe and up to $25 \%$ of the species now present will have disappeared in Southern Europe under the climatic circumstances forecasted for 2100 (Alkemade et al., 2011). Warming climate might eventually transform the subalpine Abies fabric forest into Betula utilis forest that is widely distributed in the eastern Tibetan Plateau mountainous areas with the relatively lower elevation, while subalpine forests might move to higher and colder areas, which are currently tundra (Wang et al., 2011). According to TRIPLEX-Management model, climate change at the southern edge of the boreal forest in North America may enhance the $\mathrm{C}$ sequestration rate if there are no severe drought events (Wang et al., 2012). An investigation in Peninsular Spain indicated that recent warming has reduced growth rate and $C$ accumulation, especially in wet areas (Veyreda et al., 2012). Simulation of current and future distributions of 15 tree species in Iberian Peninsula showed that large changes in species ranges and forest communities might occur, not only at high elevations within Mediterranean mountains but also along the entire elevation gradient throughout this region, particularly at low and mid-elevations (Ruiz-Labourdette et al., 2012).

It is widely predicted that the geographic distributions of tree species and forest types will undergo substantial shifts in future (Vanderwel and Purves, 2013). Forest mortality related to climate change is an increasingly common global phenomenon (Kerhoulas et al., 2013). Tropical forests and subtropical forests are threatened by their lack of resilience against long-term climate change owing to predicted reductions in rainfall and increased tree mortality (Zhou et al., 2013). Mean summer temperatures increased $1.0^{\circ} \mathrm{C}$ from 1938 to 2009 in northeastern Siberia and the rising temperatures over the second half of the 20th century enhanced plant growth along the northeast Eurasian boreal margin (Berner et al., 2013). Results from evaluating the relative impact of climate and economic changes on mountain regions in Switzerland imply that forest will be strongly influenced by the direct impact of climate change, but that changes in land use will have a comparatively small impact (Bodin et al., 2013). Responses of individual trees and whole-forest ecosystems to $\mathrm{CO}_{2}$ and climate manipulations often vary by age, implying that forests of different ages will respond differently to climate change (Anderson et al., 2013). Time-series remote sensing imagery of Poyang Lake from 2000 to 2012 showed that areas of submerged vegetation expanded with a significant average annual change rate of $23.51 \mathrm{~km}^{2}$ (Chen et al., 2014).

In this paper, a method for high accuracy surface modeling (HASM) is used to create surfaces of mean annual temperature (MAT), mean annual precipitation (MAP) and potential evapotranspiration ratio (PER); then Holdridge life zone (HLZ) model is operated on these HASM-created surfaces to simulate spatial distribution of ecosystems. This approach is termed as HASM-HLZ, which is a combination of deterministic and statistically based models.

\section{Material and methods}

\subsection{Data}

106 meteorological stations were available over and around the Jiang-Xi province during the period from 1951 to 2010 (Fig. 1), of

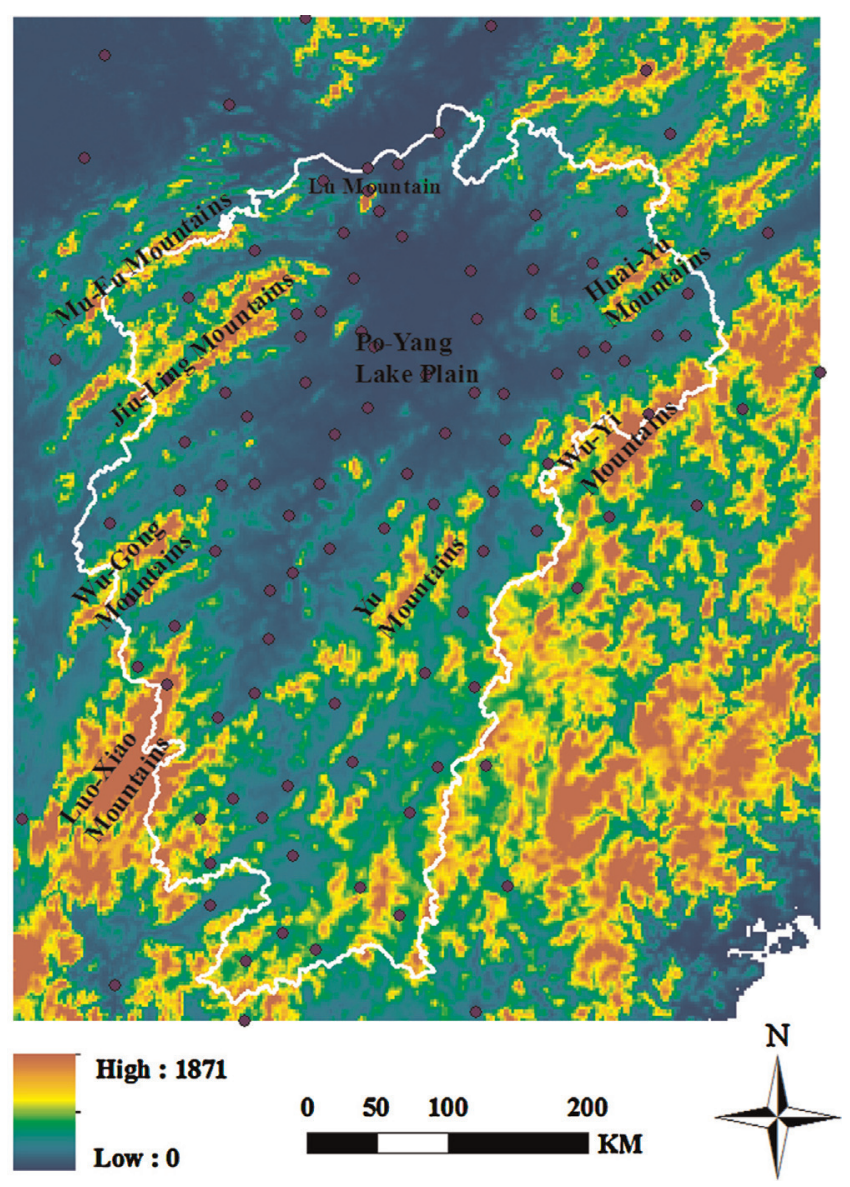

Fig. 1. DEM and meteorological stations (marked as dots) scattered over and around Jiang-Xi province. 
which 85 stations are located within Jiang-Xi province and 21 stations around Jiang-Xi province. These stations can provide daily temperature and precipitation data. The mean annual temperature (MAT) and the mean annual precipitation (MAP) at every meteorological station are calculated in terms of the daily temperature and precipitation data during the period from 1951 to 2010. We downscaled a digital elevation model (DEM) of Jiang-Xi province at a spatial resolution of $90 \mathrm{~m} \times 90 \mathrm{~m}$ from the Shuttle Radar Topography Mission (SRTM) (http://srtm.csi.cgiar.org). The DEM at a spatial resolution of $250 \mathrm{~m} \times 250 \mathrm{~m}$ is developed by means of a cubic convolution resampling approach. The DEM was used as auxiliary data to interpolate MAT and MAP from the stations to grid cells at the spatial resolution of $250 \mathrm{~m} \times 250 \mathrm{~m}$.

\subsection{Mathematical models}

Three mathematical models are employed in analyzing responses of ecosystems to climate change, which are the improved-HLZ model (Yue et al., 2005), a scaling diversity model (Yue and Li, 2010) and a mean center model (Yue et al., 2007). The HLZ model is defined by mean annual biotemperature (MABT) in degrees centigrade, mean annual precipitation (MAP) in millimeters, and potential evapotranspiration ratio (PER) logarithmically, i.e.,

$d_{i}(x, y)=\sqrt{\left(T(x, y)-T_{i}\right)^{2}+\left(P(x, y)-P_{i}\right)^{2}+\left(\mathrm{PE}(x, y)-\mathrm{PE}_{i}\right)^{2}}$

where $T(x, y)=\ln \operatorname{MABT}(x, y), \operatorname{MABT}(x, y)$ is MABT at a grid cell of $(x$, $y$ ); $P(x, y)=\ln \operatorname{MAP}(x, y), \operatorname{MAP}(x, y)$ represents MAP at a grid cell of $(x$, $y) ; \quad \operatorname{PE}(x, y)=\ln \operatorname{PER}(x, y), \quad \operatorname{PER}(x, y)=58.93 \operatorname{MABT}(x, y) / \operatorname{MAP}(x, y)$ represents PER at a grid cell of $(x, y) ; T_{i}, P_{i}$ and $\mathrm{PE}_{i}$ are respectively standards of MABT logarithm, TAP logarithm and PER logarithm at the central point of the $i$ 'th life zone in the hexagonal system of HLZs; when $d_{k}(x, y, t)=\min _{i}\left\{d_{i}(x, y, t)\right\}$, the site $(x, y)$ is classified into the $k^{\prime}$ th life zone.

The scaling diversity model is formulated as,

$D(\varepsilon, r, t)=-\frac{\ln \left(\sum_{i=1}^{m(\varepsilon, r, t)}\left(p_{i}(\varepsilon, r, t)\right)^{1 / 2}\right)^{2}}{\ln \varepsilon}$

where $p_{i}(\varepsilon, r, t)$ is proportion of area of the ith ecotope to area of the whole investigation region; $m(\varepsilon, r, t)$ is total number of HLZs under investigation; $t$ represents time; $\varepsilon=(e+A)^{-1}, A$ is area of the investigation region measured by hectare; $r$ is spatial resolution of the used data set; and e equals 2.71828 .

The mean center model is formulated as,

$x_{j}(t) \sum_{i=1}^{I_{j}} \frac{s_{i j}(t) \times X_{i j}(t)}{S_{j}(t)}$

$y_{j}(t)=\sum_{i=1}^{I_{j}} \frac{S_{i j}(t) \times Y_{i j}(t)}{S_{j}(t)}$

where $t$ is the variable of time; $I_{j}(t)$ is patch number of the HLZ type $j ; s_{i j}(t)$ is area of the ith patch of the HLZ type $j ; S_{j}(t)$ is total area of HLZ type $j ;\left(X_{i j}(t), Y_{i j}(t)\right)$ is longitude and latitude coordinate of the geometric center of the $i$ th patch of the HLZ type $j ;\left(x_{j}(t), y_{j}(t)\right)$ is the mean center of HLZ type $j$.

\subsection{Cross-validation}

A trend surface is created by operating the geographically weighted regression on the data transformed by Box-Cox approach. Target surfaces are defined respectively by adding the trend surface to the residue surfaces optimized respectively by HASM, OK, IDW and Spline (Yue et al., 2013). A cross-validation method is employed to test the target surface of HASM by comparing with the ones of OK, IDW and Spline.

Cross-validation is comprised of four steps: (i) $10 \%$ of the meteorological stations in Jiang-Xi province were removed for validation prior to model creation, (ii) MAT and MAP from 1951 to 2010 are respectively simulated at a spatial resolution of $250 \mathrm{~m}$ $\times 250 \mathrm{~m}$ using the remaining $90 \%$ of meteorological stations in Jiang-Xi province and 21 stations around Jiang-Xi province, (iii) MAE and MRE are calculated using the 10\% validation set, and (iv) the $10 \%$ validation set is returned to the pool of available station for the next iteration. This process is repeated until MAT and MAP at all meteorological stations have been simulated and the simulation error statistics for each station can be calculated. The average errors are formulated as follows,

MAE $=\frac{1}{8 \times J} \sum_{j=1}^{J}\left(\sum_{i=1}^{8}\left|\mathrm{sf}_{i, j}-f_{i, j}\right|\right)$

MRE $=\frac{1}{8 \times \mathrm{J}} \sum_{j=1}^{J}\left(\sum_{i=1}^{8}\left|\frac{\mathrm{sf}_{i, j}-f_{i, j}}{f_{i, j}}\right|\right)$

where MAE represents mean absolute error; MRE mean relative error; $\mathrm{sf}_{i, j}$ is the simulated value of the $i$ th validation grid cell in the $j$ th sampling group; $f_{i, j}$ is the observed value of the $i$ th validation grid cell in the $j$ th sampling group; $J$ represents the repeat times.

The cross-validation results indicate that HASM has a much higher accuracy comparing with the classic methods such as IDW, OK and Spline (Table 1). During the period from 1951 to 2010, MAE of the MAT simulated by HASM is $0.27^{\circ} \mathrm{C}$ and lower respectively $4 \%$, $7 \%$ and $30 \%$ than the ones by IDW, OK and Spline; MAE of the MAP simulated by HASM is $37.21 \mathrm{~mm}$ and less $11 \%, 6 \%$ and $41 \%$ than the ones by IDW, OK and Spline, respectively.

\section{Results and discussion}

\subsection{Change trend of mean annual temperature}

In terms of the simulation results from HASM, MATs were $17.05^{\circ} \mathrm{C}$ in the period from 1951 to 1980 and $17.46^{\circ} \mathrm{C}$ from 1981 to 2010. The MAT increased by $0.41^{\circ} \mathrm{C}$. Although the difference of MAT between the grid cell with the highest MAT and the grid cell with lowest MAT is $12.27^{\circ} \mathrm{C}$ in P1 and $12.92{ }^{\circ} \mathrm{C}$ in $\mathrm{P} 2,99.975 \%$ of grid cells became warmer in Jiang-Xi province, in which P1 and P2 represent the two sub-periods from 1951 to 1980 and 1981 to 2010 , respectively.

In the sub-period of P1, grid cells at which MAT was less than $16^{\circ} \mathrm{C}$ mainly distributed in Jiu-Ling mountains, Mu-Fu mountains, Huai-Yu mountains, Wu-Yi mountains, Wu-Gong mountains, LuoXiao mountains and Yu mountains, accounting for $14.73 \%$ of total area of Jiang-Xi province. Grid cells at which MAT was warmer than $18^{\circ} \mathrm{C}$ mainly located in valleys and hilly areas of Gan-Zhou and JiAn, accounting for $16.58 \%$ of the total area. MAT in most part of

Table 1

Comparative analysis of HASM errors.

\begin{tabular}{llrrrr}
\hline Weather element & Errors & HASM & IDW & Kriging & Spline \\
\hline \multirow{2}{*}{ MAT } & MAE $\left({ }^{\circ} \mathrm{C}\right)$ & 0.27 & 0.28 & 0.29 & 0.35 \\
& MRE $(\%)$ & 1.72 & 1.83 & 1.86 & 2.16 \\
MAP & MAE (mm) & 37.21 & 41.42 & 39.37 & 52.54 \\
& MRE $(\%)$ & 2.29 & 2.53 & 2.39 & 3.20 \\
\hline
\end{tabular}




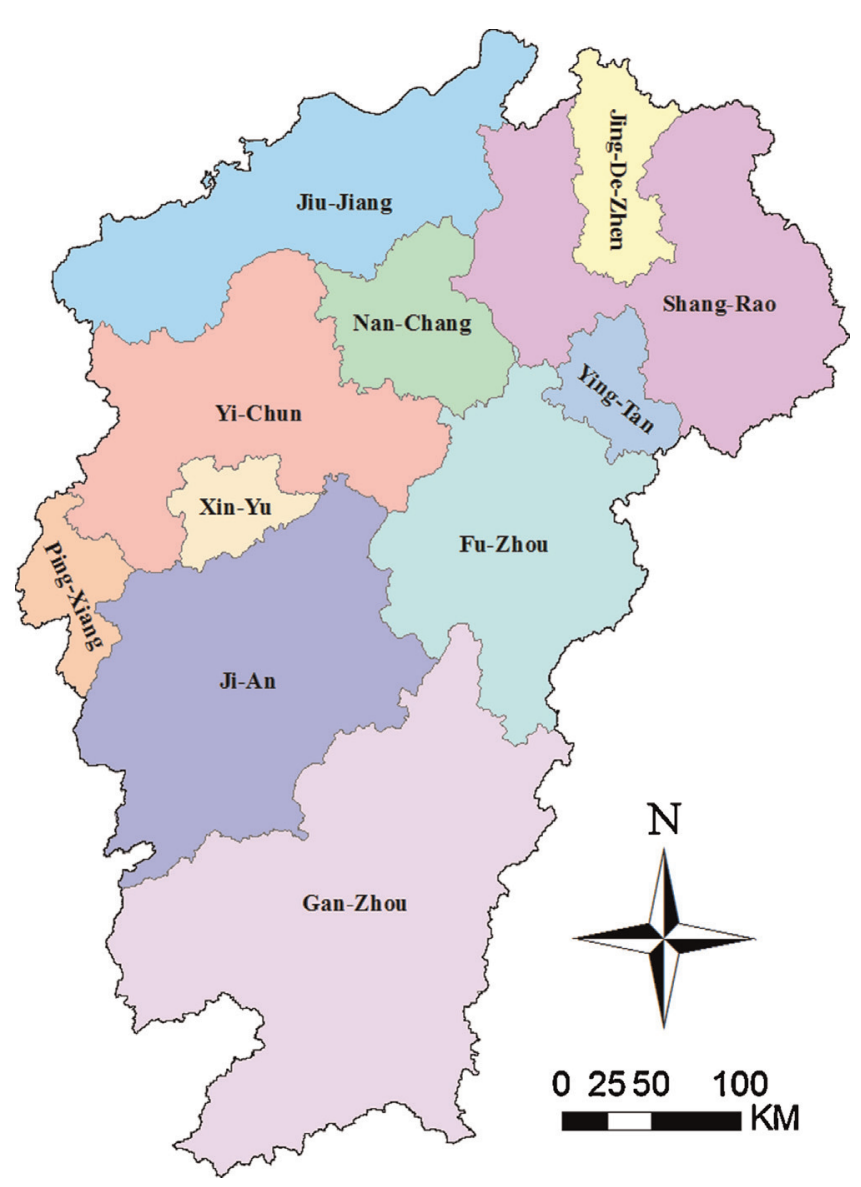

Fig. 2. The districts of Jiang-Xi province.

(a)

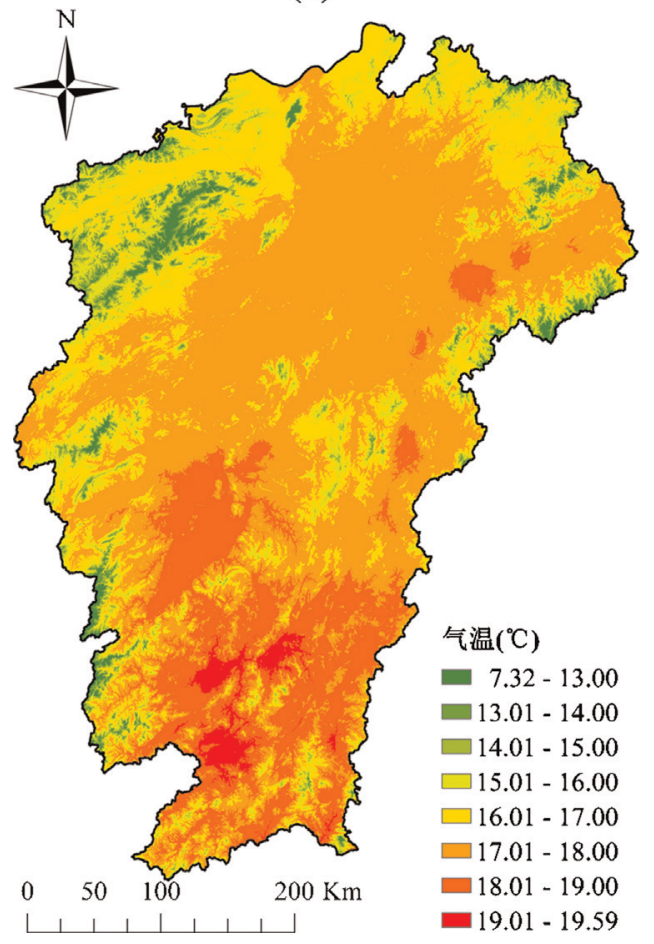

Jiang-Xi province was between $16{ }^{\circ} \mathrm{C}$ and $18{ }^{\circ} \mathrm{C}$, accounting for $59 \%$ (Figs. 2 and 3 ).

In the sub-period of $\mathrm{P} 2$, grid cells less than $16^{\circ} \mathrm{C}$ distributed in Jiu-Ling mountains, Mu-Fu mountains, Huai-Yu mountains, Wu-Yi mountains, Wu-Gong mountains and Luo-Xiao mountains as before, but they accounted for only $10.57 \%$ of total area, shrunk back $28.24 \%$ comparing with the one in P1. In addition to Gan-Zhou and Ji-An, MAT became higher than $18^{\circ} \mathrm{C}$ at many grid cells in Ying-Tan Jing-De-Zhen, Fu-Zhou, Nan-Chang, Yi-Chun and Xin-Yu, which accounted for $34.78 \%$ of the total area and increased by $109.77 \%$ comparing with the ones in P1. MAT in 55\% of the total area remained between 16 and $18^{\circ} \mathrm{C}$.

\subsection{Change trend of mean annual precipitation}

MAPs in the two sub-periods of P1 and P2 were respectively $1602 \mathrm{~mm}$ and $1718 \mathrm{~mm}$, increased by $116 \mathrm{~mm}$ from the period of P1 to P2. In P1, the minimum MAP at the driest grid cells was $1288 \mathrm{~mm}$ and the maximum MAP at the wettest grid cells was $2557 \mathrm{~mm}$. In $\mathrm{P} 2$, the minimum one was $1283 \mathrm{~mm}$ and the maximum was $2583 \mathrm{~mm}$. The difference between the minimum and the maximum was $1269 \mathrm{~mm}$ in P1, but $1300 \mathrm{~mm}$ in P2.

In P1, grid cells with MAP less than $500 \mathrm{~mm}$ were mainly located in basins and valleys of Jiu-Jiang, Nan-Chang, Ji-An, Yi-Chun and Gan-Zhou, accounting for $24.96 \%$ of the total area of Jiang-Xi province (Fig. 4a). Grid cells with MAP higher than $1800 \mathrm{~mm}$ located in mountainous areas of Huai-Yu, Wu-Yi, Jiu-Ling, Luo-Xiao and Yu mountains, accounting for $9.39 \%$ of the total area. MAP was between $1500 \mathrm{~mm}$ and $1800 \mathrm{~mm}$ in the most part of Jiang-Xi province, about $65.65 \%$ of the total area.

In P2, grid cells where MAP was lower than $1500 \mathrm{~mm}$ mainly distributed in southern Ji-An, northern Gan-Zhou, and around LuShan mountain in northern Jiu-Jiang, of which area accounted for $5.59 \%$ of total area and decreased by $77.6 \%$ comparing with the one in P1. Grid cells with MAP higher than $1800 \mathrm{~mm}$ mostly located in

Fig. 3. (a) MAT at a spatial resolution of $250 \mathrm{~m} \times 250 \mathrm{~m}$ in the sub-period of P1, (b) surface of MAT change from P1 to P2. 
(a)

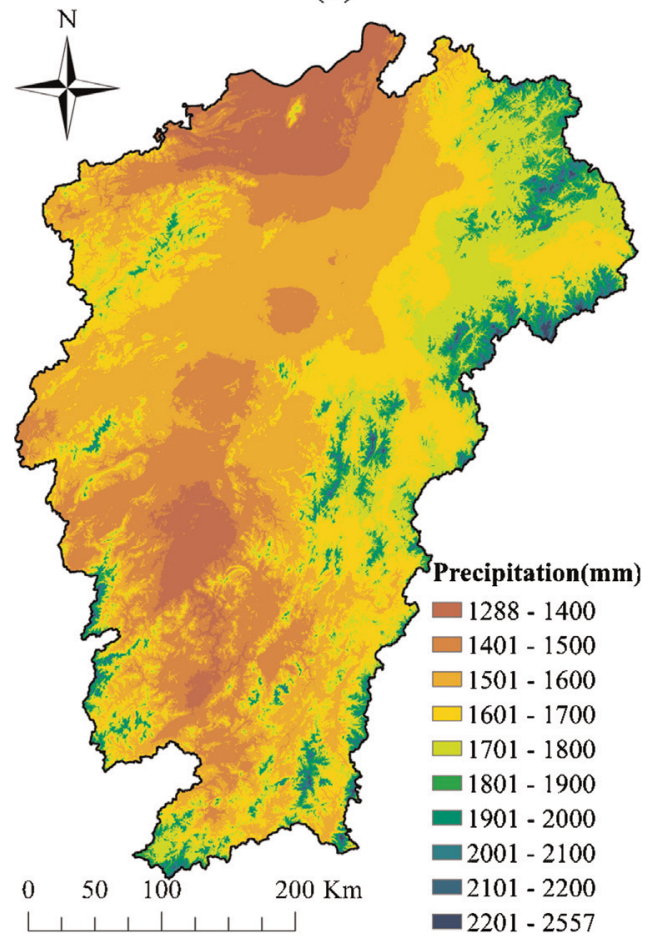

(b)

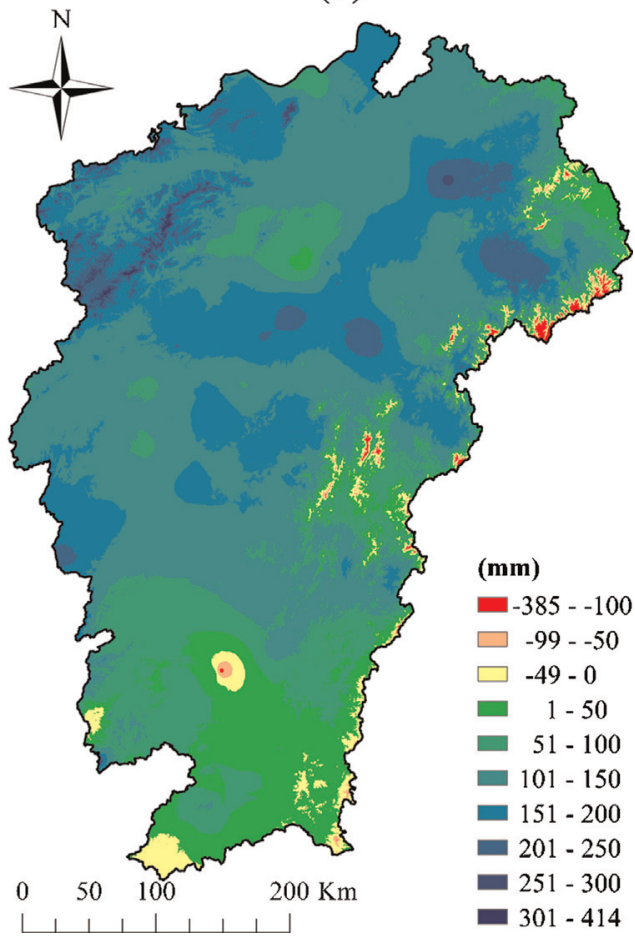

Fig. 4. (a) MAP in the sub-period of $P 1$ at a spatial resolution of $250 \mathrm{~m} \times 250 \mathrm{~m}$, (b) surface of MAP change from P1 to P2.

Jin-De-Zhen, Shang-Rao Ying-Tan Fu-Zhou and Yi-Chun as well as mountainous areas of Jiu-Ling, Mu-Fu and Luo-Xiao mountains, of which area accounted for $28.95 \%$ of the total area and increased by $208.36 \%$ comparing with the one in P1. The area with MAP between $1500 \mathrm{~mm}$ and $1800 \mathrm{~mm}$ accounted for $65.46 \%$.

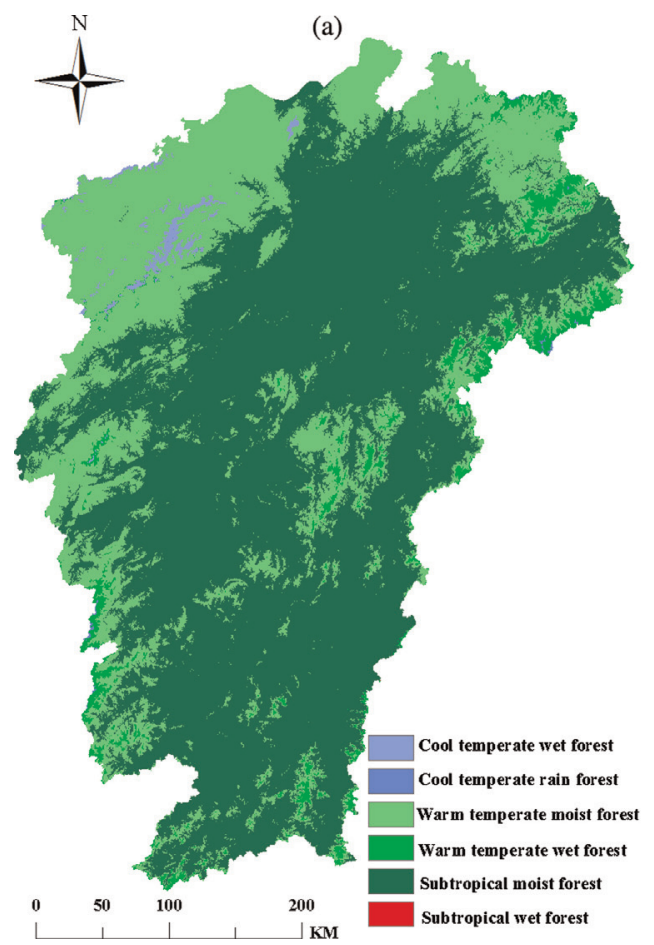

\subsection{Climate change trend}

The biggest MAT increase happened in the northern and the eastern Jiang-Xi as well as in Gan-Zhou (Fig. 3b). But some grid cells in Luo-Xiao mountains had a MAT decrease. There was the

Fig. 5. Spatial pattern of HLZ ecosystems: (a) in the period of P1; (b) in the period of P2. 
Table 2

Area change of ecosystems in Jiang-Xi province.

\begin{tabular}{|c|c|c|c|c|c|c|}
\hline \multirow[t]{2}{*}{ HLZ type } & \multirow{2}{*}{$\frac{1951-1980}{\text { Area }\left(\mathrm{km}^{2}\right)}$} & \multirow[b]{2}{*}{ Proportion (\%) } & \multirow{2}{*}{$\frac{1981-2010}{\text { Area }\left(\mathrm{km}^{2}\right)}$} & & \multirow[t]{2}{*}{ Area change $\left(\mathrm{km}^{2}\right)$} & \multirow[t]{2}{*}{ Area change rate (\%) } \\
\hline & & & & Proportion (\%) & & \\
\hline CTWF & 1092.65 & 0.66 & 12.87 & 0.01 & -1079.87 & -98.82 \\
\hline CTRF & 77.87 & 0.05 & 79.24 & 0.05 & 1.37 & 1.76 \\
\hline WTMF & 51443.15 & 30.81 & 28113.08 & 16.84 & -23332.18 & -45.35 \\
\hline WTWF & 6165.13 & 3.69 & 10640.16 & 6.37 & 4475.44 & 72.59 \\
\hline STMF & 108167.6 & 64.79 & 128089.8 & 76.73 & 19923.94 & 18.42 \\
\hline STWF & 0.56 & 0.00 & 11.87 & 0.01 & 11.32 & 2021.43 \\
\hline
\end{tabular}

largest MAP rise in Jing-De-Zhen, valley flat of eastern Shang-Rao Mu-Fu mountains and Jiu-Ling mountains as well as in some areas of Nan-Chang (Fig. 4b), while MAP became smaller in Huai-Yu mountains, Yu mountains and Wu-Yi mountains as well as in some areas of southern Jiang-Xi province.

In Jiang-Xi province, $96.815 \%$ of grid cells became warmer and wetter, 3.16\% warmer and drier, $0.024 \%$ cooler and wetter, and $0.001 \%$ cooler and drier. The grid cells becoming warmer and drier distributed in Huai-Yu mountains, Wu-Yi mountains, Yu mountains and some areas of southern Jiang-Xi province; the ones becoming cooler and wetter appeared in high altitude areas of LuoXiao mountains; the ones cooler and drier were in high altitude areas of $\mathrm{Wu}-\mathrm{Yi}$ mountains.

\subsection{Conversion of ecosystems}

6 HLZ types appeared in Jian-Xi province. They were cool temperate wet forest (CTWF), cool temperate rain forest (CTRF), warm temperate moist forest (WTMF), warm temperate wet forest (WTWF), subtropical moist forest (STMF) and subtropical wet forest (STWF) (Fig. 5). In terms of the scaling diversity index, ecotope diversity decreased from 0.061 in P1 to 0.055 in P2.

In the period of $\mathrm{P} 1, \mathrm{CTWF}$ was $1092.75 \mathrm{~km}^{2}$, mainly distributed in alpine areas of Jiu-Ling, Mu-Fu and Wu-Gong mountains as well as Lu-Shan mountain; in P2, CTWF shrank to $12.88 \mathrm{~km}^{2}$, of which area decreased by 99\%; larger part of the changed CTWF was converted into WTMF and smaller part of the changed CTWF was converted into CTRF. CTRF appeared in alpine areas of Jiu-Ling, LuoXiao, Wu-Yi and Huai-Yu mountains; its area was increased from $77.88 \mathrm{~km}^{2}$ in $\mathrm{P} 1$ to $79.25 \mathrm{~km}^{2}$ in P2 (Table 2).

WTMF and STMF were dominant ecosystems, accounting for 96\% of the total area in P1 and 94\% in P2; they distributed in plains and low mountain areas of Jiang-Xi province. WTMF decreased from $51,447.81 \mathrm{~km}^{2}$ in $\mathrm{P} 1$, which accounted for $33 \%$ of the total area, to $28,115.63 \mathrm{~km}^{2}$ in $\mathrm{P} 2$, which accounted for $17 \%$ of the total area. Most of the changed WTMF was converted into STMF. STMF was expanded from $108,177.44 \mathrm{~km}^{2}$ in P1 to $128,101.38 \mathrm{~km}^{2}$ in P2; STMF proportion increased from $65 \%$ to $77 \%$ of the total area.

WTWF mostly distributed in subalpine areas of Jiu-Ling, Mu-Fu, Wu-Yi, Huai-Yu and Luo-Xiao mountains. Its area was expanded from $6165.91 \mathrm{~km}^{2}$ in P1 to $10,641.13 \mathrm{~km}^{2}$. Much MTMF and CTWF was converted into WTWF because of the increases of MAT and MAP. WTWF increased by $73 \%$ from P1 to P2. STWF was the most stable ecosystem in Jiang-Xi province and had almost no change in the past 60 years.

Owing to impact of warming mainly, $1073.6 \mathrm{~km}^{2}$ of CTWF was converted to WTWF, distributing in high altitude areas of Lu mountain, Mu-Fu mountains, Jiu-Ling mountains and Wu-Gong $19866.63 \mathrm{~km}^{2}$ of WTMF was converted to STWF, distributing in low hills of northern, western and middle Jiang-Xi province; $8.81 \mathrm{~km}^{2}$ of WTWF was changed to STWF, distributing in southern Gan-Zhou.

Because it became warmer and drier at grid cells accounting for $0.042 \%$ of Jiang-Xi province, $56.75 \mathrm{~km}^{2}$ of WTWF was changed to STMF, which mainly distributed in southern boundary of Jiang-Xi province; $13.63 \mathrm{~km}^{2}$ of CTRF was converted into WTWF, distributing in high altitude areas of Huai-Yu mountains and Wu-Yi mountains.

Caused by becoming warmer and wetter at grid cells accounting for $0.002 \%$ of Jiang-Xi province, $3.06 \mathrm{~km}^{2}$ of WTMF transferred into STWF distributing in middle altitude areas of Wu-Yi mountains. Owing to the decrease of MAT and the increase of MAP at grid cells accounting for $0.005 \%$ of total area of Jiang-Xi province, $8.75 \mathrm{~km}^{2}$ of WTWF changed to CTRF, distributing sporadically in high altitude areas of Luo-Xiao mountains. Because of the decease of MAP, $0.56 \mathrm{~km}^{2}$ of STWF converted into STWF distributing sporadically in mountainous areas of southern Gan-Zhou; $12.06 \mathrm{~km}^{2}$ of CTRF changed into CTWF and mainly distributed in high altitude areas of Wu-Yi mountains.

$82.81 \%$ of the ecosystems were changed because of warming, $15.29 \%$ because of wetting, $1.58 \%$ because of drying, $0.28 \%$ because of warming and drying, and $0.01 \%$ because of warming and wetting (Fig. 6, Table 3).

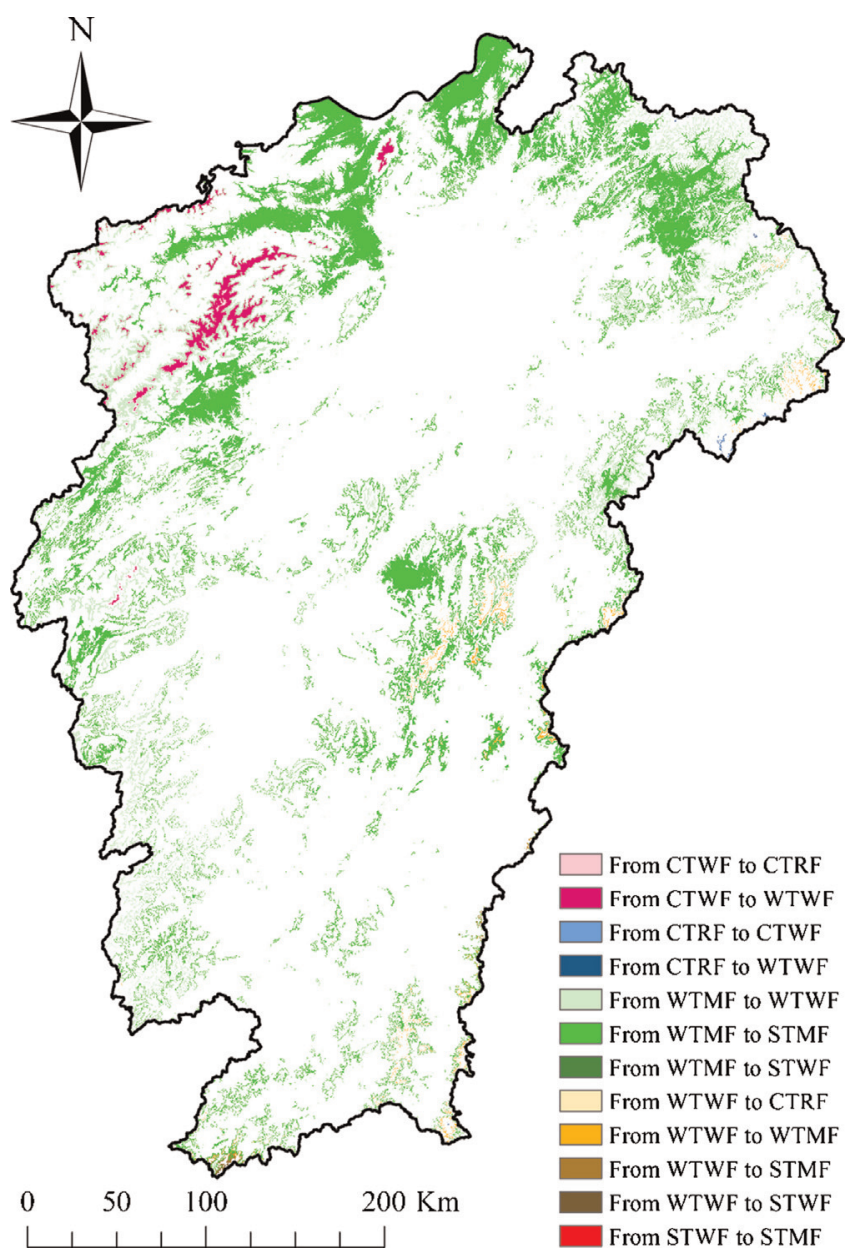

Fig. 6. Conversion of ecosystem types between the periods from 1951 to 1980 and from 1981 to 2010 . 
Table 3

Conversion of ecosystem types between the periods from 1951 to 1980 and from 1981 to 2010 (unit: number of grid cells).

\begin{tabular}{lrrrrrl}
\hline & CTWF & CTRF & \multicolumn{1}{c}{ WTMF } & WTWF & STMF & STWF \\
\hline CTWF & 13 & 193 & 0 & 0 & 0 & 0 \\
CTRF & 293 & 835 & 0 & 140 & 0 & 0 \\
WTMF & 0 & 0 & 443657 & 6193 & 0 & 0 \\
WTWF & 17178 & 218 & 61593 & 91269 & 0 & 0 \\
STMF & 0 & 0 & 317866 & 908 & 1730839 & 9 \\
STWF & 0 & 0 & 49 & 141 & 0 & 0 \\
\hline
\end{tabular}

\subsection{Shift of ecosystem mean center}

Mean center of CTWF was located in northern Jiu-Ling mountains in P1. It moved $291 \mathrm{~km}$ toward southeast in P2 and then located in the northern Wu-Yi mountains, which means that most of CTWF in Jiu-Ling, Mu-Fu and Wu-Gong mountains as well as Lu mountain disappeared in P2, but mainly distributed in Wu-Yi mountains (Fig. 7). CTRF was distributed in the northwestern Yu mountains in P1 and shifted $104 \mathrm{~km}$ toward southwest in P2; then it was located in the southeast of Wu-Gong mountains, which indicates that area of CTRF had considerably decreased in Wu-Yi, Huai-Yu and Yu mountains. The mean centers of WTMF and STMF, which were the dominant ecosystems in Jiang-Xi province, had a little shift; they moved respectively $21 \mathrm{~km}$ toward southwest and $17 \mathrm{~km}$ toward north during the period from P1 to P2. WTWF shifted $79 \mathrm{~km}$ toward northwest in P2 comparing with in P1, and moved from northeastern $\mathrm{Yu}$ mountains to northeast of Wu-Gong

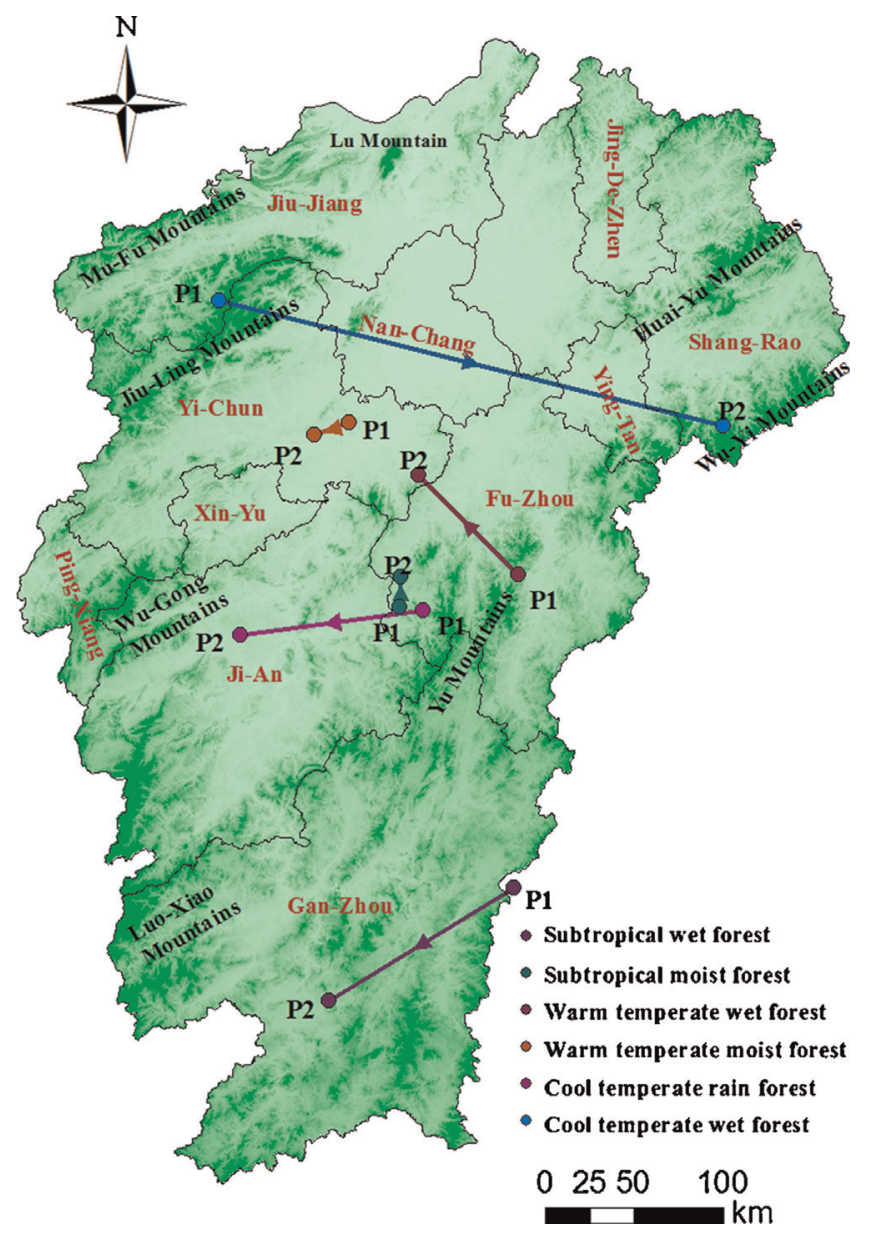

Fig. 7. Shift of mean center of ecosystem. mountains. STWF shifted $122 \mathrm{~km}$ toward southwest and its location moved from east of Gan-Zhou to southwestern Gan-Zhou.

In short, the ecosystems are very sensitive to climate change such as warming and wetting in Jiang-Xi province. Changes and potential changes of the ecosystems are similar to many parts of the world such as Europe, North America, Siberia and Asia. CTWF and CTRF moved to higher and colder areas. The forests have buffered from extreme drought and extreme cold events.

\section{Conclusions}

In Jiang-Xi province, MAT and MAP were respectively $17.23^{\circ} \mathrm{C}$ and $1661 \mathrm{~mm}$ from the year of 1951 to 2010 . MATs were $7.45^{\circ} \mathrm{C}$ and $19.74^{\circ} \mathrm{C}$, respectively at the grid cells with the lowest temperature and the highest temperature. MAP was $1367 \mathrm{~mm}$ at the grid cell with the minimum precipitation and $2461 \mathrm{~mm}$ at the grid cell with maximum precipitation. Climate became in general warmer and wetter during the periods from P1 to P2. MAT became $0.41^{\circ} \mathrm{C}$ higher and MAP increased by $116 \mathrm{~mm}$ in the 60 years.

Owing to the climate change, areas of 6 HLZ types had a great change. Ecotope diversity decreased from 0.061 to 0.055 . CTWF had the contraction in area from $1092.65 \mathrm{~km}^{2}$ in $P 1$ to $12.87 \mathrm{~km}^{2}$, which almost disappeared. STWF expanded from almost none, of which $0.56 \mathrm{~km}^{2}$ might be created by error, to $11.87 \mathrm{~km}^{2}$. STRF had almost no change. Proportion of WTWF increased from $3.69 \%$ to $6.37 \%$.

In terms of the average results from the year of 1951 to 2010, WTMF and STMF were the dominant HLZ types in Jiang-Xi province. They accounted for $94.99 \%$ of the total area of Jiang-Xi province. The proportion of WTMF decreased from $30.81 \%$ in P1 to $16.84 \%$ in P2, while STMF increased from $64.79 \%$ in $\mathrm{P} 1$ to $76.73 \%$ in $\mathrm{P} 2$.

The mean centers of the dominant HLZ types were relatively stable, while the ones of the rare HLZ types had a considerable shift. CTWF moved $291 \mathrm{~km}$ toward southeast, CTRF $104 \mathrm{~km}$ toward west and STWF $122 \mathrm{~km}$ toward southwest.

Our further work includes, (1) the expected change in biomes by the end of this century under consideration of the climate scenarios in Jiang-Xi province, and (2) the biomes-change trend is to be verified with historical investigation data and time-series remote sensing imagery.

\section{Acknowledgments}

This work is supported by National High-tech R\&D Program of the Ministry of Science and Technology of the People's Republic of China (2013AA122003), by National Basic Research Priorities Program (2010CB950904) of Ministry of Science and Technology of the People's Republic of China, and by CSTC (2010BB0146). We would like to acknowledge the two anonymous reviewers.

\section{References}

Alkemade, R., Bakkenes, M., Eickhout, B., 2011. Towards a general relationship between climate change and biodiversity: an example for plant species in Europe. Reg. Environ. Change 11, S143-S150.

Allen, C.D., Macalady, A.K., Chenchouni, H., et al., 2010. A global overview of drought and heat-induced tree mortality reveals emerging climate change risks for forests. For. Ecol. Manage. 259, 660-684.

Anderson, T.K.J., Miller, A.D., Mohan, J.E., Hudiburg, T.W., Duval, B.D., Delucia, E.H., 2013. Altered dynamics of forest recovery under a changing climate. Global Change Biol. 19, 2001-2021.

Berner, O.T., Beck, P.S.A., Bunn, A.G., Goetz, S.J., 2013. Plant response to climate change along the forest-tundra ecotone in northeastern Siberia. Global Change Biol. 19, 3449-3462.

Bodin, J., Badeau, V., Bruno, E., Cluzeau, C., Moisselin, J.M., Walther, G.R., Dupouey, J. L., 2013. Shifts of forest species along an elevation gradient in Southeast France: climate change or standmaturation? J. Veg. Sci. 24, 269-283.

Botkin, D.B., Nisbet, R.A., 1992. Forest response to climatic change: effects of parameter estimation and choice of weather patterns on the reliability of projections. Clim. Change 20, 87-111. 
Chen, L.F., Jin, Z.Y., Michishita, R., Cai, J., Yue, T.X., Chen, B., Xu, B., 2014. Dynamic monitoring of wetland cover changes using time-series remote sensing imagery. Ecol. Inf. 24, 17-26.

Clark, D.A., 2007. Detecting tropical forests' responses to global climatic and atmospheric change: current challenges and a way forward. Biotropica 39 $4-19$.

Dixon, R.K., Wisniewski, J., 1995. Global forest systems: an uncertain response to atmospheric pollutants and global climate change? Water Air Soil Pollut. 85, 101-110.

He, H.S., Mladenoff, D.J., Crow, T.R., 1999. Linking an ecosystem model and a landscape model to study forest species response to climate warming. Ecol. Modell. 114, 213-233.

IPCC, 2013. In: Stocker, T.F., Qin, D., Plattner, G.-K., Tignor, M., Allen, S.K., Boschung, J. Nauels, A., Xia Bex, Y.V., Midgley, P.M. (Eds.), Climate Change 2013: The Physical Science Basis. Contribution of Working Group I to the Fifth Assessment Report of the Intergovernmental Panel on Climate Change. Cambridge University Press, Cambridge, United Kingdom and New York, NY, USA.

Ise, T., Moorcroft, P.R., 2010. Simulating boreal forest dynamics from perspectives of ecophysiology, resource availability, and climate change. Ecol. Res. 25, 501-511.

Iverson, L.R., Prasad, A.M., 1998. Predicting abundance of 80 tree species following climate change in the eastern United States. Ecol. Monogr. 68 (4), 465-485.

Kerhoulas, L.P., Kolb, T.E., Hurteau, M.D., Koch, G.W., 2013. Managing climate change adaptation in forests: a case study from the U.S. Southwest. J. Appl. Ecol. 50 (6) 1311-1320.

Kohyama, T, Shigesada, N. 1995. A size-distribution-based model of forest dynamics along a latitudinal environmental gradient. Vegetation 121, 117-126.

McMahon, S.M., Dietze, M.C., Hersh, M.H., et al., 2009. A predictive framework to understand forest responses to global change. Ann. N.Y. Acad. Sci. 1162, 221-236.

Parmesan, C., Yohe, G., 2003. A globally coherent fingerprint of climate change impacts across natural systems. Nature 421, 37-42.

Reed, D.D., Desanker, P.V.,1992. Ecological implications of projected climate change scenarios in forest ecosystems in northern Michigan, USA. Int. J. Biometeorol. 36, 99-107.

Ruiz-Labourdette, D., Nogues-Bravo, D., Ollero, H.S., Schmitz, M.F., Pineda, F.D., 2012. Forest composition in Mediterranean mountains is projected to shift along the entire elevation gradient under climate change. J. Biogeogr. 39, 162-176.
Shafer, S.L., Bartlein, P.J., Thompson, R.S., 2001. Potential changes in the distributions of Western North America tree and shrub taxa under future climate scenarios. Ecosystems 4, 200-215.

Simberloff, D., 2000. Global climate change and introduced species in United States forests. Sci. Total Environ. 262, 253-261.

Urban, D.L., Harmon, M., Halpern, C.B., 1993. Potential response of Pacific Northwestern forests to climatic change, effects of stand age and initial composition. Clim. Change 23, 247-266.

Veyreda, J., Martinez-Vilalta, J., Gracia, M., Retana, J., 2012. Recent climate changes interact with stand structure and management to determine changes in tree carbon stocks in Spanish forests. Global Change Biol. 18, 1028-1041.

Vanderwel, M.C., Purves, D.W., 2013. How do disturbances and environmental heterogeneity affect the pace of forest distribution shifts under climate change? Ecography 36, 1-11.

Wang, X.D., Cheng, G.W., Zhong, X.H., 2011. Assessing potential impacts of climatic change on subalpine forests on the eastern Tibetan Plateau. Clim. Change 108, 225-241.

Wang, W.F, Peng C.H., Kneesh, D.D., Larocquec, G.R., Song, X.Z, Zhou, X.L, 2012. Quantifying the effects of climate change and harvesting on carbon dynamics of boreal aspen and jack pine forests using the TRIPLEX-Management model. For. Ecol. Manage. 281, 152-162.

Yu, M., Gao, Q., Liu, Y.H., Xu, H.M., Shi, P.J., 2002. Responses of vegetation structure and primary productionof a forest transect in eastern China to global change. Global Ecol. Biogeogr. 11, 223-236.

Yue, T.X., Fan, Z.M., Liu, J.Y., 2005. Changes of major terrestrial ecosystems in China since 1960. Global Planet. Change 48, 287-302.

Yue, T.X., Fan, Z.M., Liu, J.Y., 2007. Scenarios of land cover in China. Global Planet. Change 55 (4), 317-342.

Yue, T.X., Li, Q.Q., 2010. Relationship between species diversity and ecotope diversity. Ann. N.Y. Acad. Sci. 1195, E40-E51.

Yue, T.X., Zhao, N., Ramsey, R.D., Wang, C.L., Fan, Z.M., Chen, C.F., Lu, Y.M., Li, B.L., 2013. Climate change trend in China, with improved accuracy. Clim. Change 120, 137-151.

Zhou, G.Y., Peng, C.H., Li, Y.L., Liu, S.Z., Zhang, Q.M., Tang, X.L., Liu, J.X., Yan, J.H., Zhang, D.Q., Chu, G.W., 2013. A climate change-induced threat to the ecological resilience of a subtropical monsoon evergreen broad-leaved forest in Southern China. Global Change Biol. 19, 1197-1210. 